\title{
$5-2009$
}

\section{Use of triple-site ventricular pacing in a patient with severe congestive heart failure and atrial fibrillation.}

\author{
Faizel Osman \\ University of Leicester \\ Jeilan Mohamed \\ Aga Khan University, jeilan.mohamed@aku.edu \\ G. Andre' $\mathrm{Ng}$ \\ University of Leicester
}

Follow this and additional works at: https://ecommons.aku.edu/eastafrica_fhs_mc_intern_med

Part of the Cardiology Commons

\section{Recommended Citation}

Osman, F., Mohamed, J., Andre' Ng, G. (2009). Use of triple-site ventricular pacing in a patient with severe congestive heart failure and atrial fibrillation.. Pacing and Clinical Electrophysiology, 32(5), 673-674.

Available at: https://ecommons.aku.edu/eastafrica_fhs_mc_intern_med/74 


\section{Scientific}
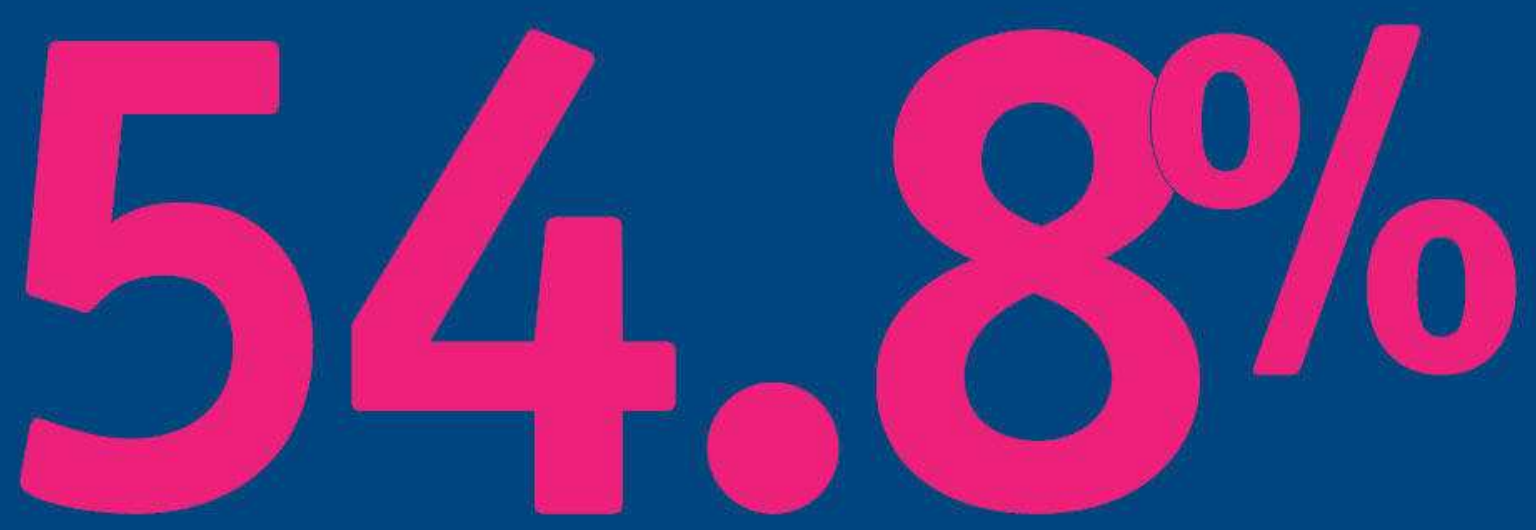

\section{of first time ICD recipients were candidates for S-ICD. ${ }^{1}$}

\section{VIEW NOW}

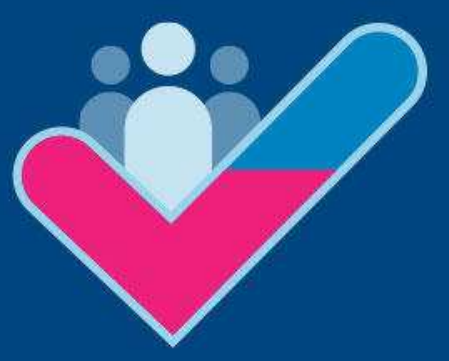

\section{REFERENCE}

1. Friedman DJ, et al. Trends and In-Hospital Outcomes Associated with Adoption of the Subcutaneous Implantable Cardioverter Defibrillator in the United States. JAMA Cardiology 2016. 


\title{
CASE REPORTS
}

\section{Use of Triple-Site Ventricular Pacing in a Patient with Severe Congestive Heart Failure and Atrial Fibrillation}

\author{
FAIZEL OSMAN, M.D., * MOHAMED JEILAN, M.B.,† and G. ANDRE NG, Ph.D.† \\ From the *Department of Cardiology, University Hospital Coventry, Coventry, UK; and the +Department of \\ Cardiology, Glenfield Hospital, University Hospitals of Leicester, Leicester, UK
}

Cardiac resynchronization therapy (CRT) has become an accepted treatment for selected patients with drug-resistant heart failure. Data for patients in atrial fibrillation (AF) remains limited but suggests benefit in these patients too. We report the case of an 82-year-old patient with heart failure, VVIR permanent pacemaker, and permanent $A F$ who had an upgrade to triple-site CRT implantation with good clinical response. Triple-site ventricular pacing may enhance the chance of response and $L V$ reverse remodeling and should be considered in AF patients undergoing CRT implantation. (PACE 2009; 32:673-674)

\section{Cardiac resynchronization therapy, triple-site ventricular pacing}

\section{Case Report}

An 82-year-old man with previous mitral valve replacement (bioprosthesis), permanent atrial fibrillation (AF), and single-chamber VVIR permanent pacemaker presented with increasing breathlessness. His pacemaker had been implanted in 2004 for bradycardia associated with AF. On questioning he had New York Heart Association class IV heart failure symptoms despite optimal medical therapy. On examination he was in cardiac failure, and resting 12-lead electrocardiogram showed a paced ventricular rhythm (QRS duration $180 \mathrm{~ms}$ ) with underlying AF. His pacing check revealed he was requiring right ventricular pacing $91 \%$ of the time. Transthoracic echocardiography with his intrinsic rhythm (intrinsic QRS duration $150 \mathrm{~ms}$ ) revealed severe left ventricular impairment (ejection fraction $<30 \%$ ) and mild mitral regurgitation. Coronary angiography revealed only mild-to-moderate coronary artery disease with no revascularization targets.

Given these findings he underwent cardiac resynchronization therapy (CRT) upgrade. During implantation coronary venography revealed poor distal target vessels; however, a small posterolateral branch and anterior branch were noted and an attempt was made to place two left ventricular (LV) pacing leads. A unipolar Medtronic 4193 (Minneapolis, MN, USA) LV lead was inserted into a posterolateral branch with excellent pacing/sensing data with a second Medtronic $4193 \mathrm{LV}$ lead positioned in an anterior branch, again with

\footnotetext{
Address for reprints: Dr. Faizel Osman, M.D., Department of Cardiology, Glenfield Hospital, University Hospitals of Leicester, Leicester LE3 9QP, UK. Fax: 44-116-287-5792; e-mail: faizel.osman@btinternet.com

Received August 8, 2008; revised October 2, 2008; accepted October 24, 2008.
}

excellent data (Fig. 1). The two LV leads and right ventricular lead were connected to a Guidant Contak Renewal (Boston Scientific, Natick, MA, USA) pulse generator with the shortest programmable AV delay of $10 \mathrm{~ms}$ and placed into a prepectoral pocket. The patient's symptoms improved almost immediately and he remains well at follow-up.

CRT has become an accepted treatment for selected patients with drug-resistant heart failure. ${ }^{1}$ Data for patients in AF remain limited but suggest benefit in these patients too. The recently published TRIP-HF (Triple Resynchronization in Paced Heart Failure Patients) ${ }^{2}$ study compared triple-site stimulation-two epicardial transvenous leads placed on the anterior and lateral or posterolateral LV wall and one right ventricular

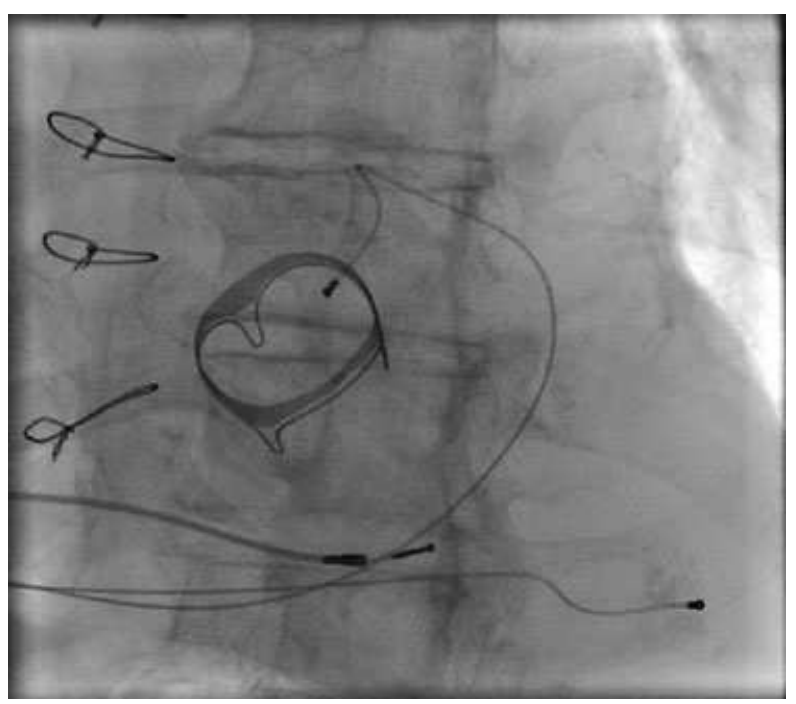

Figure 1. Left anterior oblique projection showing two unipolar left ventricular leads placed in the posterolateral and anterior coronary venous system.

(C)2009, The Authors. Journal compilation (C)2009 Wiley Periodicals, Inc. 
lead with conventional biventricular pacing. The study enrolled patients with severe heart failure presenting with a slow ventricular rate during $\mathrm{AF}$ and showed that compared with dual-site biventricular pacing, triple-site ventricular stimulation promoted further LV reverse remodeling

\section{References}

1. Vardas PE, Auricchio A, Blanc JJ, Daubert JC, Drexler H, Ector H, Gasparini M, et al. Guidelines for cardiac pacing and cardiac resynchronization therapy: The task force for cardiac pacing and cardiac resynchronization therapy of the European Society of Cardiology developed in collaboration with the European Heart Rhythm Association. Eur Heart J 2007; 28:2256-2295. as assessed by LV end-systolic and end-diastolic volumes and ejection fraction, at 3-month followup. Triple-site ventricular pacing may enhance the chance of response and LV reverse remodeling and may be considered in AF patients undergoing CRT implantation.

\footnotetext{
2. Leclercq C, Gadler F, Kranig W, Ellery S, Gras D, Lazarus A, Clémenty J, et al. TRIP-HF (Triple Resynchronization in Paced Heart Failure Patients) study group. A randomized comparison of triple-site versus dual-site ventricular stimulation in patients with congestive heart failure. J Am Coll Cardiol 2008; 51:1455-1462.
} 